\title{
EFFECTS OF FIBRE INCLUSION ON STRESS STRAIN BEHAVIOUR OF A COMPACTED OVER-CONSOLIDATED CLAY FROM LAMBETH GROUP
}

\author{
A.EKINCI ${ }^{1}$ and P.M.V. FERREIRA ${ }^{2}$ \\ ${ }^{1}$ Department of Civil, Environmental \& Geomatic Engineering, University College London, \\ $U K$. \\ E-mail:a.ekinci@ucl.ac.uk \\ ${ }^{2}$ Department of Civil, Environmental \& Geomatic Engineering, University College London, \\ $U K$. \\ E-mail:p.ferreira@ucl.ac.uk
}

\begin{abstract}
Micro reinforcement in clays is an area that needs further research as little is known about the undrained behaviour of such composite materials, especially when compaction is concerned. This work presents preliminary data from isotropically consolidated undrained triaxial tests in reinforced and unreinforced compacted samples in the laboratory. The clay used in the tests is a heavily overconsolidated clay from the Lambeth Group. In order to mimic the in situ conditions, created by the use of a rotovator to mix the fibres with the soil, samples were prepared by chopping the clay into small peds ( 10 to $15 \mathrm{~mm}$ ) that were mixed with the fibres and dynamically compacted to form triaxial samples of $100 \mathrm{~mm}$ in diameter and $200 \mathrm{~mm}$ in height.
\end{abstract}

The analysis of the triaxial testing results provided an insight into how the inclusions of fibres change the failure mechanism of the compacted soil. Reinforced samples show a strain-hardening behaviour throughout the whole shearing stage while the unreinforced samples present a reduction in deviatoric stress at higher strains, characteristic of strain localisation. The results also show that the reinforced samples generate higher pore water pressures during the shearing stage, indicating that they have a higher tendency to compress than the unreinforced samples.

Keywords: clay, fibres, laboratory tests, reinforced soils, compaction.

\section{Introduction}

Slope failures, due to pore-water dissipation, stress relaxation and desiccation cracks, are one of the major problems commonly observed on the UK road network. The necessary remediation works cause congestion and delays that, in turn, cause an annual financial loss estimated at $£ 30$ billion and increasing every year. In order to reduce the recurrent maintenance time during slope stability work, Mouchel and Highways Agency, industrial partners on this project, did a pilot field project to remediate slope failures using artificial polypropylene fibres mixed and compacted with natural soil.

The standard fibre-reinforced soil is generally defined as a soil mass containing randomly distributed fibres that provide an improvement in the mechanical behaviour of the soil composite (Li, ( 2005a).

Extensive research has been performed on reinforced sandy soils with numerous types of fibres. However, there is lack of knowledge in understanding the effects of discrete fibre reinforcement 
on heavily over-consolidated clays and the effects of in-situ mixing and compaction techniques in the response of the composite soil. Such understanding will provide an effective guidance in the construction and remediation of slopes, reducing reoccurring maintenance works and costs on the road network. It is not, however, the scope of this paper to compare in-situ with laboratory behaviour.

This paper presents initial data from laboratory undrained triaxial tests on compacted Lambeth Group clay reinforced with polypropylene fibres.

\section{Background}

Freilich and Zornberg ( 2010) studied the effects of fibre inclusion in Eagle Ford clay and a Silty Brown clay. Triaxial specimens were statically compacted with a moisture content $2 \%$ lower than the optimum, and the effects of the fibre inclusion were visually observed during the shearing stage. These authors concluded that unreinforced specimens developed a failure plane while reinforced specimens tended to bulge. In a similar study, Tang et al. ( 2008) investigated the undrained shear strength behaviour of an expansive soil reinforced with synthetic fibres. The authors' observations of the failure mode of the specimens also revealed that unreinforced samples frequently fail with the formation of a shear plane without giving a clear warning in advance. For the reinforced samples, however, the formation of a shear failure plane is not obvious. Similar findings were shown by Ozkul and Baykal ( 2007) on samples of a kaolin rich clay reinforced with rubber fibres. The authors have shown that unreinforced specimens tested in both drained and undrained conditions develop distinct slip planes whereas reinforced specimens tested drained show a barrelling type failure; those tested undrained show the partial development of a shear plane. They also reported that a limiting, confining pressure exists beyond which the presence of fibres tends to degrade the strength of the clay. Maher and Gray ( 1990) also examined the effect of confining pressure on the response of fibre-reinforced sand specimens under static loading. The findings indicated that the reinforced sands show a bilinear envelope dependant on the aspect ratio of the fibres. The same behaviour was also reported by Li and Zornberg, ( 2005) and Ozkul and Baykal ( 2007).

Chen and Loehr ( 2008) conducted triaxial tests on reinforced and unreinforced specimens of Ottawa sand. The results show that reinforced specimens have higher excess pore pressures than unreinforced specimens. The authors also posited that during the undrained shearing, medium and dense specimens show a strain-hardening behaviour up to $20 \%$ strain; while unreinforced loose specimens showed peak strengths around $2 \%$, followed by a noticeable strain softening. This behaviour has also been seen by Kumar and Everett ( 2003). In another study, Li and Zornberg ( 2003) found that the addition of fibres has significantly increased the peak shear strength and limited the post peak loss of strength on both cohesive and granular soils. These authors reported an increase in strain at failure, due to the addition of fibres and, consequently, a more ductile behaviour. Further, Zornberg et al. ( 2010) concluded that pore water pressure, generated within the soil specimens, under undrained shearing, were consistently higher for the reinforced specimens. In all three articles mentioned above, the increase of pore water pressure is related to the effect of the fibres distributing stresses within the soil mass and therefore increasing the contractive deformation within the fibre soil mixture. 


\section{Experimental Procedure}

The soil used in this study was obtained from an embankment of the junction between Motorways M25 and M1, north of London. It is an overconsolidated clay from the Lambeth Group, classified as high plasticity inorganic Clay $(\mathrm{CH})$. Liquid limit and Plastic limit of the clay found to be 59.5 and 24.1 respectively and the specific gravity is 2.65 . The grain size distribution is fairly uniform with $95 \%$ passing $0.05 \mathrm{~mm}, 85 \%$ passing $0.015,60 \%$ passing $0.004 \mathrm{~mm}$ and $46 \%$ passing $0.001 \mathrm{~mm}$. The polypropylene fibres used in this investigation have a width of $4 \mathrm{~mm}$, length of $63 \mathrm{~mm}$ and thickness of about $0.021 \mathrm{~mm}$.

Undrained triaxial tests were carried out using two Bishop Wesley triaxial apparatuses; one to test reinforced samples of $100 \times 200 \mathrm{~mm}$ and a smaller one to test unreinforced soil samples with $38 \times 79 \mathrm{~mm}$.

To simulate the in-situ procedure used to compact the soil with fibres, the retrieved samples were chopped into small peds of 10 to $15 \mathrm{~mm}$ diameter. These peds were used to create the reinforced and unreinforced samples by compaction on a cylindrical mould with a diameter of $100 \mathrm{~mm}$ and $200 \mathrm{~mm}$ height, with a compaction effort equivalent to the light compaction described in the BS 1377-4:1990. Smaller triaxial samples were trimmed using a lathe. Full details of the soil properties, sample preparation, apparatus and testing programmes are given by Ekinci \& Ferreira (2012)

\section{Results}

\subsection{Stress-strain response}

The analysis of the triaxial testing results has provided an insight into how the inclusion of fibres changes the failure mechanism of the samples. Figure 1 shows the deviatoric stress against axial strain of the undrained triaxial test. As can be seen, all reinforced samples show a strainhardening behaviour throughout the whole shearing stage, while the unreinforced samples, tested at confining stresses of 150,300 and $500 \mathrm{kPa}$ present a reduction in deviatoric stress at strains higher than $14 \%$, characteristic of strain localisation.

The same behaviour was observed by Ozkul and Baykal (2007) and the difference in behaviour was attributed to the effect of fibres in the potential shearing zone; these stretch across the shearing area and restrict the development of a slip plane by transferring some of the shear stress and strains to zones further away. A limitation to the contribution of the fibres in the deviatoric stress has also been seen in Figure 1. This behaviour is similar to what was observed by Maher and Gray (1990) and Li and Zornberg (2005); for lower confining stress (100kPa in this series of tests), the reinforced sample reached higher deviatoric stresses then the unreinforced sample tested at the same confining stresses. In contrast, above this value of confining stress $(150,300$ and $500 \mathrm{kPa}$ ), the unreinforced samples present a higher deviatoric stress than the maximum stress achieved by the reinforced samples. 


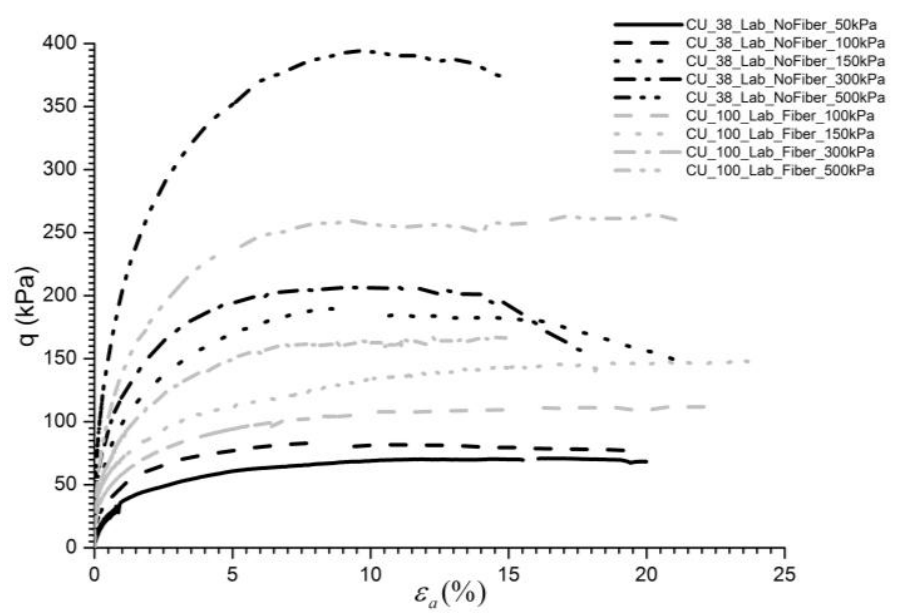

Figure 1: Stress-strain response of Lambeth Group clay and fibre-reinforced clay samples.

\subsection{Failure Mode}

The analysis of the test specimens at the end of the shearing stage enabled the visualisation of the failure modes taking place during shearing. A sketch of the sheared specimen was done at the end of every test, in order to represent, as best as possible, the failure mode of each sample (Figure 2). The results are similar to the results obtained by Zornberg, Freilich \& Li ( 2010), Tang et al. (2008), and Ozkul and Baykal (2007). At small strains, small shear planes or cracks become visible through the membrane, at the centre of the reinforced specimens. As the shear progresses, the shear planes spread along the sample and sample barrelling takes place. Even at $20 \%$ strain, there is no obvious single shear plane visible. The unreinforced samples, however, show the formation of a distinct shear plane from around 5\% strain onwards. Fibre reinforcement on soils causes stresses on the soil mass to be redistributed, transferring stresses along a much wider area, restricting the development of a shear zone and changing the failure mode of the samples.

The failure mode observations in this study are comparable to Zornberg et al. (2010). Ozkul and Baykal (2007) correlated the failure mode of the specimens to the initial moisture content, the plastic limit and the loading condition during testing. However, Ozkul and Baykal (2007) failure mode proposition, regarding to different failure modes on wet or dry side of the Plastic limit, does not agree with the results in this paper.

\subsection{Pore pressure response}

The pore water pressure generated within the reinforced soil samples, during shearing, were consistently higher than the unreinforced samples (Figure 3). The higher pore water pressures generated are related to the effect of fibres on the sample deformation. Li ( 2005b) attributed this increase in pore pressures on the fibres distributing stresses within the soil mass and therefore increasing the contractive deformations within the fibre-soil matrix. This also provides evidence that the deformation characteristics of a soil might influence how well fibres affect the composite behaviour. 


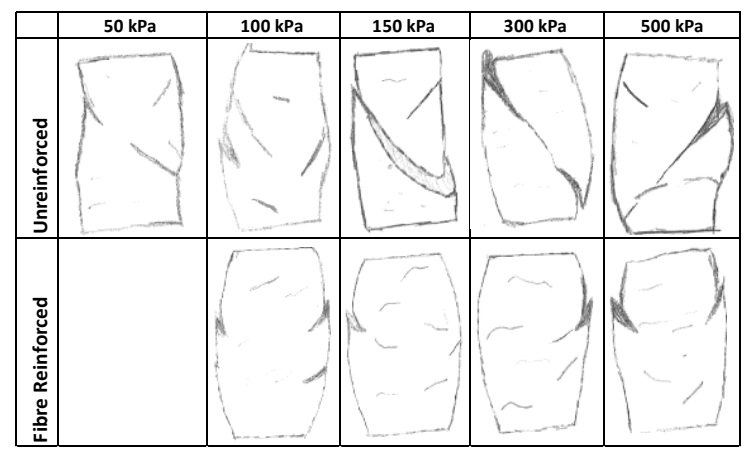

Figure 2: Shear plane characteristics for triaxial test of reinforced and un-reinforced samples

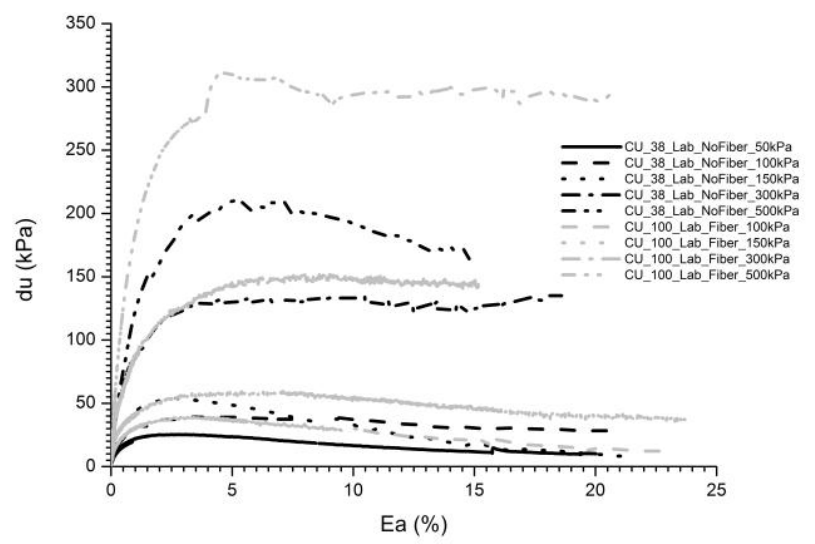

Figure 3: Pore-pressure response of Lambeth Group clay and fibre-reinforced clay samples.

Additionally, failure mechanisms are in agreement with pore water pressure distribution on each sample. In unreinforced samples, at strains around which the shear plane is formed, the pore water pressures start to drop slightly as the water drains towards the shear zone (Figure 4a) and this excess water causes a reduction in shear stress (Sandroni, 1977). For the fibre-reinforced samples, a shear plane is not formed due to the tensile strength provided by the fibres (Figure $4 b)$.
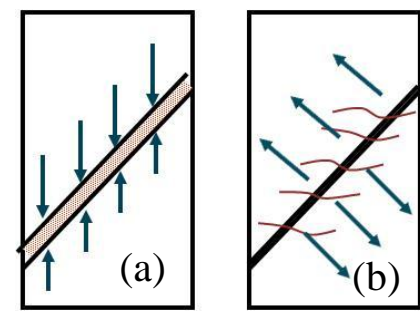

Figure 4: Pore pressure distribution illustration: (a) unreinforced specimen; (b) reinforced specimen. 
B. Indraratna, C. Rujikiatkamjorn and J S Vinod (editors)

\section{Conclusions}

The following conclusions are drawn from this investigation work:

(i) For a confining stress of up to $100 \mathrm{kPa}$, the reinforced samples showed higher shear strength than the unreinforced samples; for stresses of 150, 300 and 500, the presence of fibres tends to degrade the shear strength and the shear strength of the unreinforced samples is higher than the reinforced ones.

(ii) The reinforced specimens show a higher contractile behaviour and, consequently, a tendency to generate higher excess pore water pressure when compared to the unreinforced samples.

(iii) The addition of reinforcement changes the failure mode of the specimens by transferring stresses to other areas of the sample, restricting the formation of a shear plane.

\section{References}

Chen, C. W. \& Loehr, J. E. 2008, "Undrained and Drained Triaxial Tests of Fiber-reinforced Sand," pp. 114120.

Ekinci, A. \& Ferreira, P. M. V. (2012).The undrained mechanical behaviour of a fibre-reinforced heavily over-consolidated clay Proceedings to International Symposium on Ground Improvement, In ISSMGE TC 211 International Symposium on Ground Improvement.

Kumar, S. \& Everett, T. (2003). Strength Characteristics of Silty Clay Reinforced with Randomly Oriented Nylon Fibers. EJGE Paper, 10,

Li, C. \& Zornberg, J. G. (2003).Validation of Discrete Framework for Fiber Reinforcement. Proceedings of the 2003 North American Conference on Geosynthetics.

Li, C. \& Zornberg, J. G. (2005).Interface Shear Strength in Fiber-Reinforced Soil Proceedings of the Sixteenth International Conference of Soil Mechanics and Geotechnical Engineering (ISSMGE), Osaka, Japan: pp. 1373-1376.

Li, C. 2005a. Mechanical Respons of Fiber-Reinforced Soil. (Ph.D Thesis). The University of Texas at Austin.

Li, C. 2005b. Mechanical Respons of Fiber-Reinforced Soil. (Ph.D Thesis). The University of Texas at Austin.

Maher, M.H. \& Gray, D.H. (1990). Static Response of Sands Reinforced with Randomly Distributed Fibers. Journal of Geotechnical Engineering, 116, (11)

Ozkul, Z.H. \& Baykal, G. (2007). Shear Behavior of Compacted Rubber Fiber-Clay Composite in Drained and Undrained Loading. Journal of Geotechnical and Geoenvironmental Engineering, 133, (7)

Tang, Y. H., Bao, C. G., Wang, M. Y., \& Ding, J. H. (2008).Experimental Study on the Strength Characteristics of Expansive Soil Reinforced With Synthetic Fibers 4th Asian Regional Conferance on Geosynthetics, In 4th Asian Regional Conferance on Geosynthetics, pp. 369-373.

Zornberg, J. G., Freilich, B. J., \& Li, C. (2010).Effective Shear Strength of Fiber-Reinforced Clays. Proceedings of the 9th International Conference on Geosynthetics, In 9ICG, pp. 1997-2000. 